http://jmscr.igmpublication.org/home/

ISSN (e)-2347-176x ISSN (p) 2455-0450

crossref DOI: https://dx.doi.org/10.18535/jmscr/v7i9.135

Journal Of Medical Science And Clinical Research

IGM Publication

An Official Publication of IGM Publication

\title{
Clinical and Operative Study of Intracranial Complications of Chronic Suppurative Otitis Media (CSOM) and its Management
}

\author{
Authors
}

\author{
Dr V. P. Narve ${ }^{1}$, Dr Priyanka Verma ${ }^{2}$, Dr Vivek Verma ${ }^{3}$ \\ ${ }^{1}$ Professor and Head, Department of ENT, GRMC, Gwalior \\ ${ }^{2}$ PG Resident, Department of ENT, GRMC \\ ${ }^{3} \mathrm{~S}$ R, Department of Surgery, GRMC \\ *Corresponding Author \\ Dr Priyanka Verma \\ PG Resident, Department of ENT, GRMC
}

\begin{abstract}
Introduction: Chronic suppurative otitis media (CSOM) is defined as chronic ear discharge more than 12 weeks through perforated tympanic membrane .the cycle of infection, inflammation, granulations tissues and cholesteatoma formation continues, destroying surrounding bony margins and ultimately leading to various complications of CSOM. ${ }^{1}$ Despite the availability of newer antibiotics CSOM can still leads to major complications in developing countries. ${ }^{5}$

Objectives: The aim and objective of this study is to study clinical presentation and intra-operative study of intracranial complications of chronic suppurative otitis media.(warning signs and symptoms, the etiological agents) and its management.

Method: This is a prospective cross sectional study carried out in department of E.N.T, Jayarogya Hospital during the period of one year from Jan 2018 to Dec 2018. All admitted cases of Intracranial complications due to CSOM of all age \& gender were included. After confirmation of complication by CT/MRI, multidisciplinary approach was followed including initial treatment by systemic antibiotics up to definitive final treatment by mastoid surgery.

Results: Out of 23 patients of CSOM with Intracranial complications the age of patients ranged from 1070 years with majority i.e. $65.21 \%$ being between 20-30years adult age group with male predominance was $69.59 \%$. Majority of patients belong to poor socio-economic status. Otorrhea was present in all patients i.e. $100 \%$, followed by hearing loss. Brain abscess were found in $60.8 \%$ was the most common complication followed by meningitis (30.4\%). In operative findings erosion of sinus plate $34.7 \%$ followed by dura platel tegmen plate erosion were found $30.4 \%$.

Conclusion: Brain abscess (60.8\%) out of which (34.7\%) were temporal lobe abscess were commonest intracranial complication followed by meningitis. It is important to study the pathogenesis of CSOM with complications as it is still high in young age group \& low socio-economic strata, especially in rural population. With advent of new specific antibiotics \& new diagnostic modalities it's prevalence \& incidence has decreased.

Keywords: CSOM, CT/MRI,CBC, AURAL SWAB C/S, CSF.
\end{abstract}

\section{Introduction}

CSOM is defined as chronic inflammation of middle ear \& mastoid cavity which present with recurrent ear discharge through a perforated tympanic membrane. Infection, inflammation, granulation, polyp \& cholesteatoma formation 
continue destroying bony margins ultimately leading to various complications of $\mathrm{CSOM}^{1}$. WHO defines CSOM as otorrhea of atleast 2 weeks, but ENT surgeons tend to adapt a longer duration of more than 3 months of active disease ${ }^{2}$. CSOM is the most common disease entity in our JAH, ENT Dept. Middle ear cleft which is separated by the thinnest shell bone from dura of middle ear\& posterior cranial fossa. The tegmen tympani gets demineralised during acute infection \& suffers resorption. Infection also spreads through infected clots within small veins through bone \& dura to venous sinuses. Another way of spread is through the normal anatomical pathway i.e. through oval $\&$ round window into internal auditory canal, cochlea, vestibular aqueduct, dehiscence of thin bony covering of jugular bulb, dehiscence of tegmen tympani and suture line of temporal bone. ${ }^{3}$

All patients with CSOM with cholesteatoma have to be surgically managed with mastoidectomy to prevent intracranial complications. If not managed timely cholesteatoma will erode tegmen \& cause complication. cases of CSOM symptomatically not relieved by antibiotics indicates possibilities of onset of spread of infection to the intracranial compartments. onsets of intracranial complications of otitis media are heralded by danger signals or warning sign as headache, fever, vomiting, fever, drowsiness \& visual field defect.

Over the past few decades, an apparent increase in increase in incidence has been noticed but it is attributable to the early diagnosis and hence better management of the condition.

\section{Materials and Method}

This prospective cross sectional study was carried out in Dept. Of ENT, Jayarogya Hospital, Gwalior a tertiary care hospital during the period of one year from January 2018 to December 2018. Total 23 patients of CSOM associated with intracranial complications were included in the study. A thorough history was taken and detailed otologic, neurologic \& general physical examination was carried out and recorded on Proforma. Pure tone audiogram, computed tomography (CT) scan of brain and temporal bone, MRI brain plane \& contrast, lumbar puncture, complete CBC (complete blood count) were done in all patients. Routine aural swab for $\mathrm{C} / \mathrm{S}, \quad \mathrm{X}$-ray bilateral mastoid, fundoscopy, CSF analysis were done in case of patient presenting with signs of Intracranial complications.

\section{Following parameters were analyzed}

1) Demographic profile: age at presentation, gender.

2) Clinical profile: duration of disease, type of intracranial complication, treatment received, age of diagnosis, operative findings.

\section{Results}

During study period total 23 patients of intracranial complication of CSOM mean age of presentation was 26.2 years i.e. younger age group with male predominance $16 / 23$ i.e. $69.6 \%$.
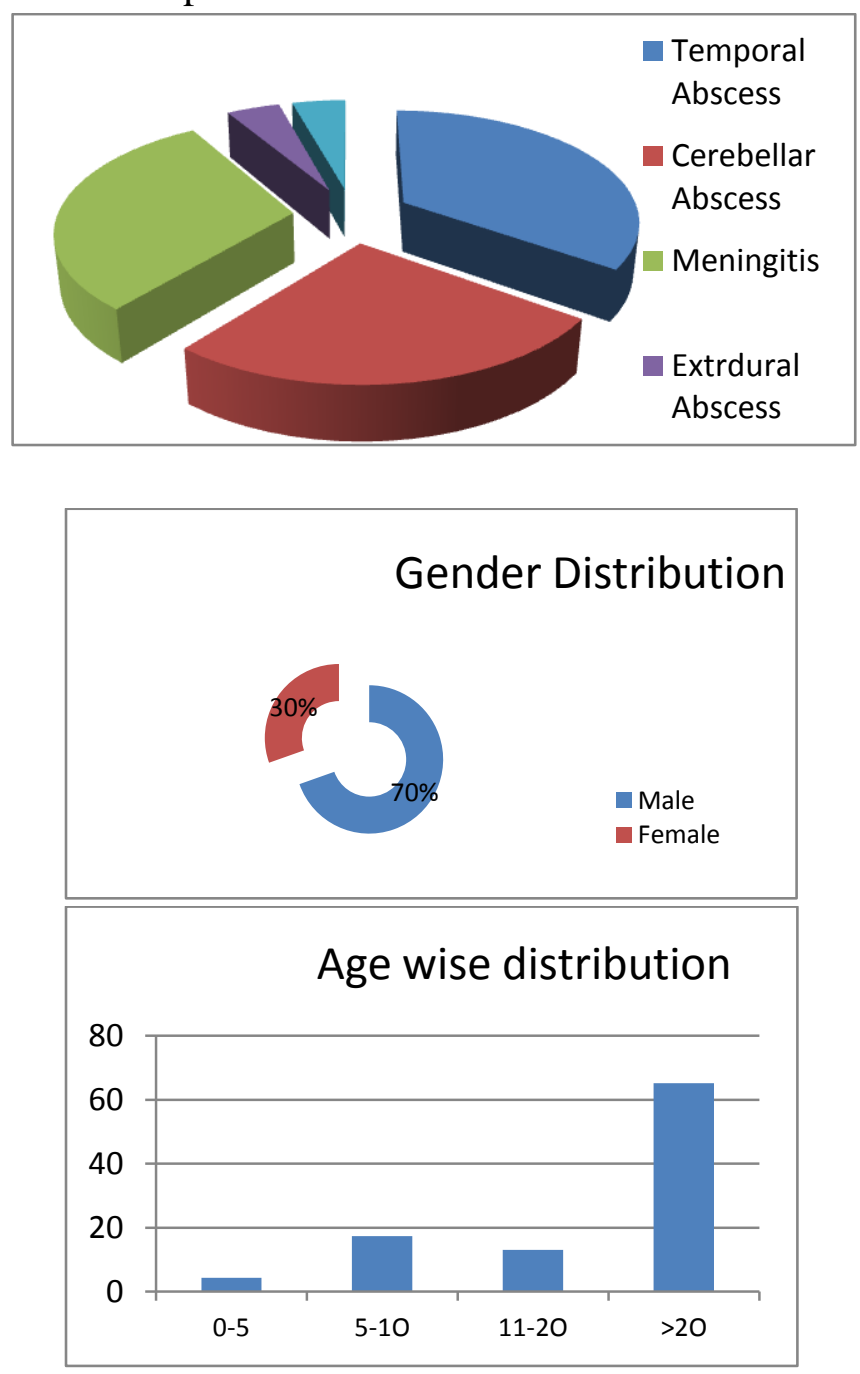


\section{Brain Abscess}

Emergency burr hole and drainage was done in Neurosurgery Dept. Pus was sent for C/S followed by canal wall down modified radical mastoidectomy was done at earliest opportunity. All cases of meningitis were managed conservatively by neurophysician by appropriate i.v systemic antibiotics. Mastoidectomy was done after all the signs of meningitis subsided.

\begin{tabular}{|c|c|c|c|c|}
\hline & & Subcategory & $\begin{array}{c}\text { No. Of Cases } \\
(\mathrm{n}=23)\end{array}$ & $\%$ \\
\hline 1 & $\begin{array}{c}\text { Brain } \\
\text { Abscess } \\
(14)\end{array}$ & $\begin{array}{c}\text { Temporal } \\
\text { Abscess }\end{array}$ & 8 & 34.7 \\
\cline { 3 - 5 } & $\begin{array}{c}\text { Cerebellar } \\
\text { Abscess }\end{array}$ & 6 & 26 \\
\hline 2 & Meningitis & & 7 & 30.4 \\
\hline 3 & $\begin{array}{c}\text { Extradural } \\
\text { Abscess }\end{array}$ & & 1 & 4.3 \\
\hline 4 & LST & & 1 & 4.3 \\
\hline
\end{tabular}

\section{LST}

Single case of LST was reported and diagnosed by MR venogram, sinus was opened \& thrombus removed along with mastoidectomy.

Persistent headache, chronic otorrhea and features of space occupying lesion were commonest mode of presentation in these patients. Some cases of extradural abscess were asymptomatic diagnosed on imaging. On clinical examination a granulation, cholesteatoma, attic perforation were seen in majority of cases. Proteus, Pseudomonas species were the most common organisms isolated.

Table: Pus Culture findings in brain abscess cases

\begin{tabular}{|c|c|c|c|}
\hline & & $\begin{array}{c}\text { No. Of } \\
\text { cases }\end{array}$ & Percentage \\
\hline \multirow[t]{5}{*}{1} & Positve (13) & & \\
\hline & Proteus & 6 & 42.8 \\
\hline & Pseudomonas & 5 & 35.71 \\
\hline & Staphylococcus & 1 & 7.14 \\
\hline & H. Influenza & 1 & 7.14 \\
\hline 2 & Negative(1) & 1 & 7.14 \\
\hline
\end{tabular}

All patients received i.v. antibiotics for 4-6 weeks depending upon culture \& sensitivity (C/S) report. Anaerobic organisms especially Pseudomonas was isolated most commonly, play a important role in foul smelling pus discharge.
Table: Operative findings

\begin{tabular}{lc}
\hline EROSION OF & No of cases \\
\hline Sinus plate & 10 \\
Tegmen exposed & 8 \\
Sinodural angle & 2 \\
Lateral semicircular canal & 1 \\
Sigmoid sinus -thrombus material & 1 \\
Facial canal eroded & 1 \\
\hline
\end{tabular}

\section{Discussion}

CSOM complications were continued to occur and continue to be serious until diagnosed timely and interventions was done. Intracranial complication occur via number of possible route :1) demineralising property of cholesteatoma leads to bone resorption or osteitis.;2) infected clot from thombosed small vein through eroded dural plate or tegmen plate;3)through normal preformed pathway such as the labyrinth, endolymphatic channels ;4) via congenital/ developmental or traumatic bony defects.

Reason of still high mortality due to intracranial complications were septicemia /overwhelming infections. Leads to pachymeningitis / leptomeningitis followed by increased intracranial pressure leads to cerebral edema and various abscess formation leads to increased resistance to CSF drainage secondary to thrombosed sinus. Patients presents with raised blood pressure, bradycardia, loss of consciousness, alert mental status, lead to sudden death.

In the present study median age of presentation were 26.5 years i.e ,second to third decades, with male predominance $(69.56 \%)$, other study which matches our results was done by Radheshyam M et al $2015^{4}$ and vikram B $\mathrm{K}$ et al $2008^{5}$. prepondance in younger age group. The reason behind might be immature immune system to fight againt pathogenic organisms. Male predominance because they usually stay outside of home for working purpose more exposure to outer environment. late age presentation for female would be lack of access to hospital and lack of knowledge regarding the complications of CSOM. Majority of populations were belongs to low socioeconomic status, uneducated, and with poor hygiene .Brain abscess were present most 
commonly $(60.8 \%)$, followed by meningitis (30.4\%). LST and extradural abscess were present only in one cases .our study results matches with study done by some other author's study i.e , N. Sharma et al 2015(52.5\%) ${ }^{6}$ and Avani jain et al $2017(58.5 \%)^{7}$ the reason behind brain abscess most common is erosion of tegmen plate / dural plate by cholesteatoma that were present in majority of patients in our study.some other authour's study reported meningitis were most commom complication. Shushant tyagi et al $2015^{8}$ \& Anjana A. Mohit 2017. Neurosugerical drainage of intracranial abscess with removal of causative cholesteastoma, granulations by modified radical mastoidectomy was done in our institute along with culture specific antibiotics and timely intervention provide good results.

Symptoms and signs of intracranial complications were presence of an offensive ear discharge were present in all patients (100\%). Followed by hearing loss, headache, intetmittent fever, drowzyness, neck rigidity, nausea and vomiting alert the clinician to the possibility of underlying intracranial complication. A careful history and examinations is important in making diagnosis of the complications. Pseudomonas species and anaerobic organisms were isolated most commonly $42.8 \%$ followed by proteus species $35.7 \%$. anaerobic organisms flourished well in oxygen depleted environment \& responsible for foul smelling ear discharge .study done by S. Devi et al $2015{ }^{9}$ results matches with our study results. All paients were presents treated with higher parentral antibiotics and proper ear care.

In external auditory canal granulations and cholesteatoma along with attic perforation were mostly seen in our stud, cholesteatoma along with granulations over sinuses form perisinus abscess and resulted in LST which is a rare complication and were present only in one case in our study also .patient presented with high grade fever , retroorbital pain and papilloedema. CT scan shows DELTA sign by dura confirm the diagnosis (Lubiana et al ${ }^{10 .}$

Otitic hydrocephalus affected patients presented with headache, $6^{\text {th }}$ nerve palsy, diplopia, nausea vomiting and papilloedema because of raised intra cranial pressure withut affected CSF pressure .treatment is $\mathrm{i} / \mathrm{v}$ antibiotics and systemic corticosteroids. In intraoperative finding sinus plate erosion were present in $43.4 \%$ cases followed by tegmen plate erosion which matches with study done by Analgban et $\mathrm{al}^{11}$.

\section{Conclusion}

The rate of complication of chronic suppurative otitis media especially intracranial were observed significantly more in developing countries as compare to developed countries. Brain abscess were most common complication followed by meningitis. With the advent of new diagnostic modality CT/MRI \& early surgical intervention, broad spectrum antibiotics provides good result . Some author's suggests pneumococcal vaccines for elderly patients which was treated conservatively.

\section{Please cite this paper as}

Narvey V P, Verma P, Verma V. Comparison of clinical and operative study of intracranial complications of chronic suppurative otitis media (csom) and its management.

\section{Acknowledgements: Nil}

Peer Review: Not commissioned. Externally peer reviewed.

Conflicts of Interest: The authors declare that they have no competing interests

\section{References}

1. Stattery .W.H pathology and clinical courses of inflammatory disease of middle ear. In $5^{\text {th }}$ ed. ontario. BC Decker InC 2003:422-33.

2. Goycoolee MV, Heeb MM, Ruah C. Definations \& terminology otolaryngol clin North America, 1991,24 (4)757-761.

3. Dubey SP, Larawin V, complication of chronic suppurative otitis media and their management laryngoscope 2007;117 (2):264267.

4. Radheshyam M. Aloke BM intracranial complication of chronic suppurative otitis 
media in rural ara .International Journal of current medical and applied science 2015;5(3);184-187.

5. Vikram BK ;khaja N, udayashankar SG, clinicoepidemiogical study of complicated and uncomplicatedchronic suppurative otitis media . J laryngol 2008122 ;442-6.

6. N.sharma , A.A jaiswal P.K banergee A.k Garg complicatin of chronic suppurative otitis media and their management a single institution 12 years experience Indian $\mathrm{J}$. Otolaryngol head surgery 672015353 360.

7. Avani Jain, Nikhil Arora, Ravi meher, J.c Paersy, Ramanuj Bansal Intracranial complication of chronic suppurative otitis media in pediatric patients. A persisting problem in developing countries international journal of pediatric otolaryngology 1002017128131.

8. Dr Shushant tyagi ; Dr, Mohit Shrivastava ; Dr vandana singh; Dr. Lalit kumar chronic suppurative otitis media ; clinical presentation of intracranial complications in arural area Journal of evidence based medicine and health care vol 2 issue $400 \mathrm{ct}$ 052015 page 6639-6644.

9. S.Devi Prasad. V. Chandrasekhar, G Sreenivas, V. R Tagore, S.B Amarnath, G. Pryanka . a clinical study of extracranial complications of chronic suppurative otitis media J. Evidence based medicine and health care vol2 issue 24 june15 2015 page 3540-3551.

10. Lubianca Neto J.F saffer M. Rotta . FT,Araata JLF , Brinckmann CA,Ferricira P. LST and cervical abscess complicating cholesteatoma in children case report and review. International Journal of pediatric otorhinolaryngology 1998;42:263-9

11. S.Anbalagan Intracranial complications of chronic suppurative otitis media with cholesteatoma - A retrospective study ISSM(o)23395-2822 ISSN(p)2395-3814. 